\title{
REVIEW
}

\section{Cardiac output in 1998}

\author{
M Singer
}

Over 100 years ago Karl Ludwig stated that:

The fundamental problems in the circulation derive from the fact that the supply of adequate amounts of blood to the organs of the body is the main purpose of the circulation while the pressures that are necessary to achieve it are of secondary importance; but the measurement of flow is difficult while that of pressure is easy so that our knowledge of flow is usually derivatory.

Are we, in 1998, any nearer to the routine monitoring of flow? The more salient question may be whether flow measurement is actually useful in terms of clinical management or patient outcome. The wherewithal to monitor flow exists. Techniques for cardiac output measurement, albeit of varying accuracy, invasiveness and complexity, have been available commercially for the past 25 years, although their use in the UK is relatively sparse, both in intensive and coronary care units ${ }^{1}$ and operating theatres. ${ }^{2}$ The national confidential enquiry into perioperative deaths ${ }^{2}$ covering the years 1993-94 reviewed 1802 deaths occurring within 30 days of an operation. Three quarters of these patients were deemed moderate to very high risk, yet only $4.2 \%$ had a Swan-Ganz (pulmonary artery) catheter in situ during surgery.

The Swan-Ganz catheter: friend or foe? Several studies have shown outcome benefit from flow directed haemodynamic manipulation in the high risk surgical patient using either invasive ${ }^{34}$ or non-invasive ${ }^{56}$ monitoring techniques. Only sporadic studies have demonstrated an advantage for the critically ill ICU patient. ${ }^{7}$ However, a recent retrospective study by Connors and colleagues ${ }^{8}$ suggested that patients receiving a Swan-Ganz catheter on day 1 of their ICU admission were 39\% more likely to die compared with patients matched for disease and illness severity by complex statistical manipulations who did not receive the catheter. The accompanying editorial ${ }^{9}$ advocated an immediate moratorium on catheter use, a situation ${ }^{10}$ parallelling an earlier study by Gore et $a l,{ }^{11}$ who found an increase in mortality in patients with acute myocardial infarction, the only perceived change in management over historical controls being the increased use of Swan-Ganz catheters.

The study by Connors et al has been heavily criticised; nevertheless, it served as the catalyst for a recent US consensus meeting, ${ }^{12}$ which acknowledged the lack of conclusive data showing benefit or harm, yet reaffirmed its likely worth. A prospective, randomised trial rather than an immediate ban was recommended, a view supported by the US Food and Drug Administration.

It is more likely that fault, if any, lies with how the catheter is used rather than from any intrinsic damage caused by the catheter itself. To contemplate a study comparing management using the Swan-Ganz catheter against bedside clinical acumen alone undermines Ludwig's maxim and is, in my opinion, badly misdirected. A number of studies in both intensive care ${ }^{71314}$ and coronary care unit ${ }^{1516}$ populations has shown the unreliability of clinical and radiological evaluation of haemodynamic status with experienced specialists faring no better than junior staff and medical students. ${ }^{13}$ A first priority in evaluating the Swan-Ganz catheter should be to ensure adequate training. A recent European questionnaire $^{17}$ examining proper use and interpretation of data mirrored an earlier US study $^{18}$ showing that competency was highly variable, with only $70 \%$ of questions being answered correctly. Second, how the catheter is used must be addressed. At the time of Connors et al's study, ${ }^{8}$ many ICUs had adopted the supranormalised oxygen delivery philosophy advocated by Shoemaker whereby the circulation was driven with fluid loading followed by increasing doses of dobutamine to obtain predetermined raised values in cardiac index, oxygen delivery, and consumption. ${ }^{3}$ This approach proved highly successful in high risk non-cardiac surgical patients ${ }^{34}$ and was subsequently adopted by many ICUs. However, it took several years before-at best- no benefit ${ }^{19}$ and-at worst- harm $^{20}$ was demonstrated in such critically ill patients in prospective, randomised, controlled studies.

\section{Non-invasive techniques}

Several non-invasive techniques exist for flow monitoring but none has yet penetrated clinical practice to any great extent. The major issues are reliability and familiarity. Unfortunately, many commercial devices have been launched without proper validation and often with obvious design flaws. Furthermore, thermodilution, an imperfect gold standard, ${ }^{21}{ }^{22}$ which is often used imperfectly, ${ }^{17}{ }^{18}$ is often used as the comparator technique. These problems have served to undermine confidence in the various technologies, which upgraded equipment and newer models have yet to fully overcome.

The two best described techniques are Doppler ultrasound and thoracic bioimpedance. Doppler technology has enjoyed a renaissance since the advent of combined Doppler echocar- 
Table 1 Formulae used for stroke volume calculation by thoracic bioimpedance

\begin{tabular}{ll}
\hline Kubicek 1966 & $\rho \bullet \frac{\mathrm{L}^{2}}{\left(\mathrm{Z}_{0}\right)^{2}} \bullet(\mathrm{dZ} / \mathrm{dt}) \mathrm{max} \bullet \mathrm{LVET}$ \\
Sramek 1983 & $\delta \bullet \frac{\mathrm{L}^{3}}{4.25} \bullet \frac{(\mathrm{dZ} / \mathrm{dt}) \max }{\mathrm{Z}_{0}} \bullet \mathrm{LVET}$ \\
Sramek-Bernstein 1986 & $\delta \bullet \frac{0.17 \mathrm{H}^{3}}{4.25} \cdot \frac{(\mathrm{dZ} / \mathrm{dt}) \max }{\mathrm{Z}_{0}} \bullet$ LVET \\
Adjusted Kubicek 1997 & $\rho \cdot \frac{(0.17 \mathrm{H})^{2}}{\left(\mathrm{Z}_{0}\right)^{2}} \bullet(\mathrm{dZ} / \mathrm{dt}) \mathrm{max} \bullet$ LVET
\end{tabular}

$(\mathrm{dZ} / \mathrm{dt}$ )max, maximum of 1 st derivative of impedance signal; $\rho$, electrical resistivity of blood; $\mathrm{L}$, distance between two levels of electrodes; $\delta$, correction factor depending on weight; LVET; left ventricular ejection time; $\mathrm{H}$, height; $\mathrm{Z}_{0}$, basic thoracic impedance.

diography, in particular, from the transoesophageal approach, which has provided new possibilities for both diagnosis and monitoring. ${ }^{23-25}$ Some authorities advocate its superiority over invasive techniques ${ }^{26}$; however, expense, complexity, and the necessary expertise have restricted its widespread application in the UK. A simpler technique uses standalone Doppler ultrasound that interrogates the blood vessel - usually ascending or thoracic descending aorta-from suprasternal ${ }^{27}$ or oesophageal $^{29}{ }^{30}$ approaches, respectively. This enables monitoring of blood flow velocity from which a reasonable estimate of cardiac output can be made. The shape of the flow velocity waveform also readily permits assessment of left ventricular contractility and filling, and systemic vascular resistance. ${ }^{3031}$ A Starlingtype curve can be constructed from the stroke volume response to $200 \mathrm{ml}$ fluid challenges. To date, oesophageal Doppler ultrasound is the only non-invasive technology used successfully to direct intraoperative fluid loading, resulting in outcome benefit and significant reductions in hospital stay in prospective, randomised, controlled trials of cardiac ${ }^{5}$ and orthopaedic ${ }^{6}$ surgery. A relevant finding from these studies was the greater sensitivity of stroke volume over cardiac output, as compensatory tachycardia tended to maintain cardiac output in the face of mild to moderate hypovolaemia. Thus, overall, the control groups showed no change in output but had significant falls in stroke volume.

An editorial ${ }^{32}$ accompanying the hip fracture repair study ${ }^{6}$ spelled out the potential benefits of this non-invasive flow monitoring technique in high risk patients undergoing surgery, but emphasised the need for multicentre confirmation before its widespread adoption. It is worth reiterating that outcome was improved by acting on the information provided to achieve the set goal of optimal filling. Which haemodynamic goals are applicable to different patient populations (high risk surgery, severe heart failure, sepsis), and whether non-invasive techniques are equal, or even superior, to invasive monitoring techniques requires extensive study, but encouragement can be drawn from these initial investigations.

Thoracic bioimpedance has had a more chequered course. In 1966 Kubicek described the thorax as a cylinder evenly perfused with blood of specific resistivity. In 1983 Sramek demonstrated that the thorax behaves electrically more like a truncated cone. Pulsatile thoracic aortic blood flow causes negative impedance changes with a maximum rate of change during systole between pairs of electrodes placed on the neck and upper abdomen. Various new correction factors and equations have been advanced (table 1) and incorporated into commercial systems using pairs of electrodes placed around neck, thorax, and upper abdomen. Unfortunately, validation studies have produced highly inconsistent results. Generally, the technique appears to be reasonably reliable in healthy volunteers but performs unpredictably in the critically ill. ${ }^{33-37}$ Thus, the paper by Spiering et al in this issue $^{38}$ is rather surprising in view of the major discrepancy between bioimpedance and dye dilution in normal subjects. Despite the authors' assurances, I wonder if an unrecognised methodological problem affected the study outcome. If bioimpedance is to develop as a clinical tool it must address these reliability issues, alert the operator to erroneous readings, and regain user confidence.

Other techniques are also available for either intermittent or continuous monitoring of flow. Echocardiographic measurement of ventricular volumes at end systole and end diastole enables stroke volume to be measured with reasonable accuracy ${ }^{23-25}$; however, at least six different methods have been described and user expertise is a significant factor. Recently developed technology allows three dimensional reconstruction of images of the left ventricle, although ventricular volumes are still generally calculated from cross sectional and $M$ mode images, accepting assumptions about left ventricular shape.

Analysis of the contour of the aortic pulse wave allows monitoring of cardiac output, as the rate blood flows from arteries to veins is proportional to the rate of fall of arterial pressure. This can be performed non-invasively from a finger probe $^{39}$ or from an indwelling pressure transduced arterial cannula. ${ }^{40-42}$ There is not an extensive literature assessing its reliability in different conditions; furthermore, it cannot be used for measurement of cardiac output unless first calibrated against another technique.

Thermal dilution techniques can be performed without the need for pulmonary artery catheterisation, ${ }^{43}$ although validation data are scanty. A commercially available device using this technology (COLD; Pulsion, Munich, Germany also claims to measure global end diastolic volume (the sum of the end diastolic volumes of both left and right atria and ventricles), intrathoracic blood volume (a possible indicator of cardiac preload), and extravascular lung water. ${ }^{43} 44$

The Fick principle states that oxygen consumption $\left(\mathrm{VO}_{2}\right)$ equals cardiac output multiplied by the arteriovenous oxygen concentration difference. For cardiac output measurement the arterial oxygen concentration is measured from a peripheral arterial blood sample, the venous oxygen concentration from pulmonary arterial blood, and $\mathrm{VO}_{2}$ is derived from minute ventilation and inspired and expired gas analysis. ${ }^{45-48}$ In a variation of this method, $\mathrm{CO}_{2}$ production can be used instead of oxygen consumption although 
large discrepancies have been found in comparative studies in the critically ill. ${ }^{48}$ In theory, the Fick technique is the gold standard for cardiac output measurement but it is invasive and methodological error is not uncommon-for example, when high inspired oxygen concentrations are being administered. Using the indirect Fick approach, the carbon dioxide rebreathing technique is a popular technique among sports physiologists as it is totally non-invasive and more reliable at exercise than at rest. ${ }^{47}{ }^{49} 50$ The rebreathing manoeuvre is used to estimate mixed venous $\mathrm{PCO}_{2}\left(\mathrm{PVCO}_{2}\right)$, which, combined with end tidal $\mathrm{PCO}_{2}$ and $\mathrm{CO}_{2}$ production, gives a non-invasive Fick estimate of the cardiac output. Reproducibility is not as high as other techniques $^{48}{ }^{49}$ and it has yet to be applied at the bedside of the sick patient.

Finally, the dye dilution technique may enjoy renewed interest as a bedside cardiac output monitoring technique through online means of measuring plasma concentrations of indocyanine green, the standard indicator in use today. ${ }^{4455}$ Alternatively, a new approach using lithium chloride as the indicator ${ }^{5253}$ with plasma concentrations being measured by a lithium selective electrode in a flow through cell connected by a three way tap to a standard arterial cannula, may also merit consideration.

\section{Conclusion}

There is sufficient evidence to show that flow monitoring leading to directed haemodynamic management is beneficial, at least in certain patient subsets. Advantage is generally gained by those at risk of, rather than having, established organ failure, such as the high risk surgical patient. Few studies have demonstrated outcome benefit in critically ill patients in whom metabolic, inflammatory, and cellular processes are often too far advanced for benefit to be gained from haemodynamic manipulations that prevent or reverse tissue hypoxia, a potent stimulus of various inflammatory pathways. Current use of flow monitoring generally precludes pre-emptive circulatory optimisation to prevent, or at least, minimise tissue hypoxia. This is equally applicable to the trauma patient or the patient in acute heart failure, where hypovolaemia often passes unrecognised and untreated until hypotension and organ failure have supervened. Invasive measurement of cardiac output is coming under increasing scrutiny and the place of non-invasive technology merits re-appraisal in the light of newer and more reliable equipment and techniques. This should provide impetus for further investigation, particularly in patients in the early stages of illness.

1 Singer M, Bennett ED. Invasive hemodynamic monitoring in the United Kingdom. Enough or too little? Chest 1989;95:623-6.

2 Report of the national confidential enquiry into perioperative deaths (NCEPOD) 1993/1994. London: Confidential Enquiry into Perioperative Deaths, 1996.

3 Shoemaker WC, Appel PL, Kram HB, et al. Prospective trial of supranormal values of survivors as therapeutic goals in high-risk surgical patients. Chest 1988;94:1176-86.

4 Boyd O, Grounds RM, Bennett ED. A randomised clinical trial of the effect of deliberate perioperative increase of oxygen delivery on mortality in high-risk surgical patients. gen delivery on mortality

5 Mythen MG, Webb AR. Peroperative plasma volume expansion reduces the incidence of gut mucosal hypoperfusion in cardiac surgery. Arch Surg 1995;130:423-9.
6 Sinclair S, James S, Singer M. Intraoperative intravascular volume optimisation and length of hospital stay after repair of proximal femoral fracture: randomised, controlled trial. BMF 1997;315:909-12

7 Mimoz O, Rauss A, Rekik N, et al. Pulmonary artery catheterization in critically ill patients: a prospective analysis of outcome changes associated with catheter-prompted changes in therapy. Crit Care Med 1994;22:573-9.

8 Connors AF Jr, Speroff T, Dawson NV, et al. The effectiveness of right heart catheterization in the initial care of critically ill patients. SUPPORT Investigators. FAMA 1996; 276:889-97.

9 Dalen JE, Bone RC. Is it time to pull the pulmonary artery catheter? [editorial] $f A M A$ 1996;276:916-18.

10 Robin ED. Death by pulmonary artery flow-directed catheter. Time for a moratorium? [editorial] Chest 1987;92:727-31.

11 Gore JM, Goldberg RJ, Spodick DH, et al. A communitywide assessment of the use of pulmonary artery catheters in patients with acute myocardial infarction. Chest 1987;92: 721-7.

12 Pulmonary artery catheter consensus conference: consensus statement. Crit Care Med 1997;25:910-25.

13 Connors AF Jr, McCaffree DR, Gray BA. Evaluation of right heart catheterisation in the critically ill patient without acute myocardial infarction. $N$ Engl $\mathscr{f}$ Med 1983;308:263-7.

14 Eisenberg PR, Jaffe AS, Schuster DP. Clinical evaluation compared to pulmonary artery catheterisation in the haemodynamic assessment of critically-ill patients. Crit Care Med 1984;12:549-53.

15 Bayliss J, Norell M, Ryan A, et al. Bedside haemodynamic monitoring: experience in a general hospital. BMF 1983;287:187-90

16 Timmis AD, Fowler MB, Burwood RJ, et al. Pulmonary oedema without critical increase in left atrial pressure in acute myocardial infarction. BMF 1981;283:636-8.

17 Gnaegi A, Feihl F, Perret C. Intensive care physicians' insufficient knowledge of right-heart catheterization at the bedside: time to act? Crit Care Med 1997;25:213-20.

18 Iberti TJ, Fischer EP, Leibowitz-AB, et al. A multicenter study of physicians' knowledge of the pulmonary artery catheter. Pulmonary Artery Catheter Study Group. $\mathcal{F} A M A$ 1990;264:2928-32.

19 Gattinoni L, Brazzi L, Pelosi P, et al. A trial of goal-oriented hemodynamic therapy in critically ill patients. $\mathrm{SvO}_{2}$ Collaborative Group. N Engl f Med 1995;333:1025-32.

20 Hayes MA, Timmins AC, Yau EH, et al. Elevation of systemic oxygen delivery in the treatment of critically ill patients. N Engl f Med 1993;330:1717-22.

21 Stetz CW, Miller RG, Kelly GE, et al. Reliability of the thermodilution method in the determination of cardiac output in clinical practice. Am Rev Respir Dis 1982;126:1001-4.

22 Stevens JH, Raffin TA, Mihm FG, et al. Thermodilution cardiac output measurement. Effects of the respiratory cycle on its reproducibility. FAMA 1985;253:2240-2.

23 Flachskampf F. Recent progress in quantitative echocardiography. Curr Opin Cardiol 1995;10:634-9.

24 Pai RG, Shah PM. Echocardiographic and other noninvasive measurements of cardiac hemodynamics and ventricular function. Curr Probl Cardiol 1995;20:681-770.

25 Troianos CA, Porembka DT. Assessment of left ventricular function and hemodynamics with transesophageal echocardiography. Crit Care Clin 1996;12:253-72.

26 Jardin F. PEEP, tricuspid regurgitation, and cardiac output. Intens Care Med 1997;23:806-7.

27 Huntsman LL, Stewart DK, Barnes SR, et al. Noninvasive Doppler determination of cardiac output in man. Circulation 1983;67:593-602.

28 Chandraratna PA, Nanna M, McKay C, et al. Determination of cardiac output by transcutaneous continuous-wave ultrasonic Doppler computer. Am f Cardiol 1984:53:234-7.

29 Singer M, Clarke J, Bennett ED. Continuous hemodynamic monitoring by esophageal Doppler. Crit Care Med 1989;17: 447-52.

30 Singer M, Bennett ED. Non-invasive optimization of left ventricular filling by esophageal Doppler. Crit Care Med 1991;19:1132-7

31 Singer M, Allen MJ, Webb AR, et al. Effects of alterations in left ventricular filling, contractility and systemic vascular resistance on the ascending aortic blood velocity waveform of normal subjects. Crit Care Med 1991;19:1138-45.

32 Arrowsmith JE, Gan TJ. The oesophageal Doppler monitor [editorial]. BMF 1997;315:893-4.

33 Fuller HD. The validity of cardiac output measurement by thoracic impedance: a meta-analysis. Clin Invest Med 1992; 15:103-12.

34 de May C, Matthews J, Butzer R, et al. Agreement and reproducibility of the estimates of cardiovascular function by mpedance cardiography and $\mathrm{M}$-mode echocardiography in healthy subjects. Br f Clin Pharmacol 1992, 34:88-92.

35 Appel P, Kram HB, Mackabee J, et al. Comparison of measurements of cardiac output by bioimpedance and thermodilution in severely ill surgical patients. Crit Care Med 1986;14:933-5.

36 Preiser JC, Daper A, Parquier JN, et al. Transthoracic electrical bioimpedance versus thermodilution technique for cardiac output measurement during mechanical ventilation. Intens Care Med 1989;15:221-3.

37 Young JD, McQuillan P. Comparison of thoracic electrical bioimpedance and thermodilution for the measurement of cardiac index in patients with severe sepsis. $\mathrm{Br} \mathcal{F}$ Anaesth 1993;70:58-62. 
38 Spiering W, van Es PN, de Leeuw PW. Comparison of impedance cardiography and dye dilution for measuring cardiac output. Heart 1998;79:437-41.

39 Gratz I, Kraidin J, Jacobi AG, et al. Continuous noninvasive cardiac output as estimated from the pulse contour curve. $\mathcal{F}$ Clin Monit 1992;8:20-7.

40 English JB, Hodges MR, Sentker C, et al. Comparison of aortic pulse-wave contour analysis and thermodilution methods of measuring cardiac output during anaesthesia in the dog. Anesthesiology 1980;52:56-61.

41 Tannenbaum GA, Mathews, Weissman C. Pulse contour cardiac output in surgical intensive care unit patients. $\mathcal{F}$ Clin Anesth 1993;5:471-8.

42 Irlbeck $\mathrm{M}$, Forst $\mathrm{H}$, Briegel $\mathrm{J}$, et al. Continuous measurement of cardiac output with pulse contour analysis. Anaesthesist 1995;44:493-500.

43 Hoeft A, Schorn B, Weyland A, et al. Bedside assessment of intravascular volume status in patients undergoing coronary artery bypass surgery. Anesthesiology 1994;81:76-86.

44 Haller M, Zollner C, Briegel J, et al. Evaluation of a new continuous thermodilution cardiac output monitor in critically ill patients: a prospective criterion standard study. Crit cally ill patients. a prospecti

45 Neuhoff $\mathrm{H}$, Wolf $\mathrm{H}$. Method for continuously measured oxygen consumption and cardiac output for use in critically ill patients. Crit Care Med 1978;6:155-61.
46 Axler O, Tousignant C, Thompson CR, et al. Comparison of transesophageal echocardiographic, Fick, and thermodilution cardiac output in critically ill patients. F Crit Care

47 Espersen K, Jensen EW, Rosenborg D, et al. Comparison of cardiac output measurement techniques: thermodilution, Doppler, $\mathrm{CO}_{2}$-rebreathing and the direct Fick method. Acta Anaesthesiol Scand 1995;39:245-51.

48 Sherman MS, Kosinski R, Paz HL, et al. Measuring cardiac output in critically ill patients: disagreement between thermodilution-, calculated-, expired gas-, and oxygen consumption-based methods. Cardiology 1997;88:19-25.

49 Russell AE, Smith SA, West MJ, et al. Automated non-invasive measurement of cardiac output by the carbon dioxide rebreathing method: comparisons with dye dilution and thermodilution. Br Heart f 1990;63:195-9.

50 Auchinloss JH, Gilbert R, Kuppinger M, et al. Mixed venous $\mathrm{PCO}_{2}$ tension during exercise. $\mathcal{F}$ Appl Physiol 1980;48:933-

51 Iijima T, Aoyagi T, Iwao Y, et al. Cardiac output and circulating blood volume analysis by pulse dye-densitometry. $\mathcal{F}$ Clin Monit 1997;13:81-9.

52 Linton RAF, Band DM, Haire KM. A new method of measuring cardiac output in man using lithium dilution. $\mathrm{Br} f$ Anaesth 1993;71:262-6.

53 Linton R, Band D, O'Brien T, et al. Lithium dilution cardiac output measurement: a comparison with thermodilution. Crit Care Med 1997;25:1796-800.

\section{STAMPS IN CARDIOLOGY}

\section{Hypertension}

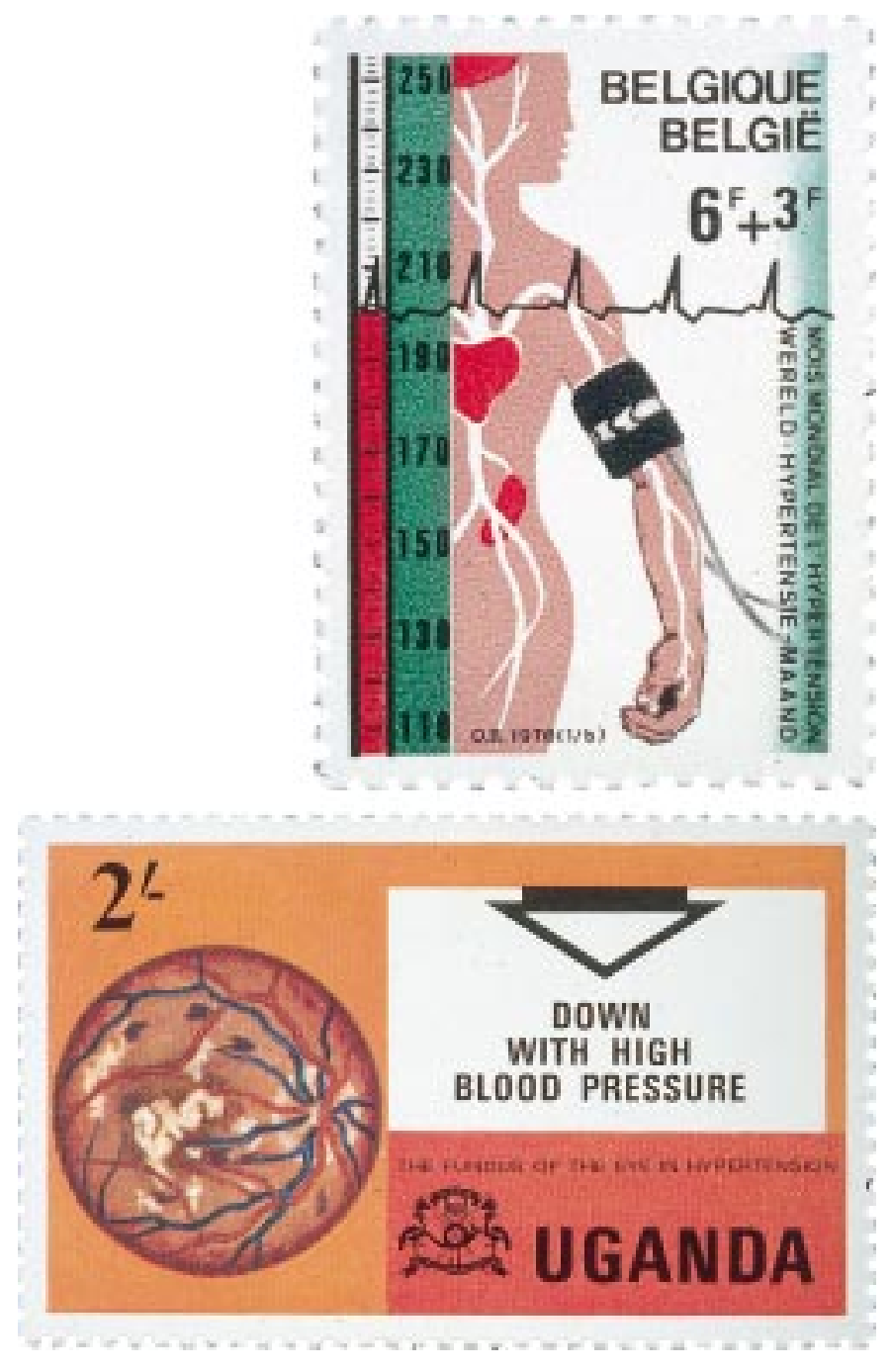

The theme for the 1978 World Health Day was "Down with high blood pressure". A number of countries issued stamps to promote this campaign. Four stamps and a miniature sheet (containing the complete set) were released by Uganda. Illustrated is the 2 shilling stamp which incorporates the campaign slogan and hypertensive retinal changes. (The other three stamps depicted a sphygmomanometer and a daily blood pressure chart, the heart in hypertension, and the kidneys and renal circulation.) Belgium issued a set of three charity stamps in 1978 for philanthropic works; the middle 6 franc value (carrying a 3 franc surcharge) contained the stamp for the World Health Day. The design incorporates the measurement of blood pressure, a stylised heart, brain, and kidney as well as the electrocardiogram. (The other two stamps in the set featured deserted children and the De Mick sanatorium (antituberculosis campaign issue).)

Hypertension and the measurement of blood pressure have appeared on a few stamps outside of the 1978 World Health Organisation theme. These include stamps from Czechoslovakia in 1952 for the National Health Service, the United Nations (Vienna headquarters) in 1988 for international volunteer day and in 1983 from the British Virgin Islands for nursing week.

M K DAVIES A HOLLMAN 